\title{
Gobernar es gestionar con calidad ${ }^{1}$
}

Jordi López Camps *

\section{Necesidad de cambio}

La gestión de la calidad en la Administración Pública, en general, y de manera particular en el ámbito local, está ganando adeptos. ¿Por qué interesa la Calidad Total en la Administración Pública? La Calidad Total en el ámbito de las Administraciones Públicas aporta una nueva perspectiva a las propuestas modernizadoras y de cambio en el sector público. Adoptar la filosofía de la calidad en la Administración Pública no es sólo aplicar las técnicas exitosas de la mejora continua en los servicios públicos; es esto y, además, releer el sentido de los servicios públicos desde una nueva lógica política, mucho más atenta a la participación y al desarrollo de la democracia. Por eso la gestión de la calidad en el sector público es una cuestión política.

El modelo de ayuntamiento imaginado y construido desde la transición democrática hasta ahora se ha ido agotando paulatinamente y hoy, cuando nos encontramos a las puertas del siglo XXI, de poco sirve ya como respuesta estructural a las distintas transformaciones operadas en el ámbito local o para responder adecuadamente a los desafíos venideros. Hoy la administración local se encuentra frente a nueva etapa de modernización. Por su amplitud y naturaleza este proceso modernizador es coherente con las corrientes que, fuera de nuestras fronteras, propugnan crear un nuevo paradigma de Administración pública.

El entorno del gobierno local se ha modificado notablemente en estos últimos años. Han surgido nuevos fenómenos que demandan respuestas creativas e innovadoras. Existen numerosos factores que presionan para que las Administraciones públicas cambien. Quisiera destacar algunos de los factores que evidencian esta necesidad de cambio en el modelo de Administración pública y de gobierno municipal.

- Influencia de los factores económicos. Las haciendas locales se encuentran al borde del colapso financiero y existe una importante presión social para reducir el déficit público. Se pide que las Administraciones públicas trabajen mejor y cuesten menos.

- Impacto de las nuevas tecnologías. Los ciudadanos no entiender que si en el sector privado las nuevas tecnologías lian servido para mejorar su productividad y alcanzar nuevas cotas de competitividad, por qué no sucede lo mismo en las Administraciones públicas. La ciudadanía confía que nuevas tecnologías ayuden a resolver algunos de los problemas endémicos del sector público.

- Búsqueda de una nueva legitimidad politica. El Estado del Bienestar keynesiano ha entrado en crisis por la pérdida del consenso que justificó su aparición. La crisis del actual modelo de Estado del Bienestar obliga a las fuerzas políticas a buscar nuevas bases de consenso entre los distintos agentes sociales, políticos y económicos sobre cuál debe ser el rol de una Administración pública moderna. La crisis del modelo de bienestar también cuestiona el modelo de gobernabilidad utilizado en las últimas décadas. La ciudadanía reclama mayor incidencia en la toma de decisiones y una revisión profunda de los canales clásicos de participación política.

- Nuevo sentido de lo local. A pesar de la globalización del mercado, la escala territorial se convierte en un elemento importante para el desarrollo de la actividad económica, el bienestar social o para crear un nuevo consenso político y promover la aparición de una nueva dimensión de la política. El territorio también ha adquirido un nuevo significado. Este fenómeno altera los métodos clásicos de gobierno y gestión de las corporaciones locales, introduciendo conceptos clave como el marketing city para sustentar sus proyectos de desarrollo económico y social. Es en el ámbito de actuación territorial donde el ayuntamiento mejor puede garantizar la calidad de vida deseada por los ciudadanos y donde también se dilucidan importantes inversiones económicas que resultan 
trascendentales para el desarrollo del municipio. La competitividad empresarial está también ligada a la gestión municipal. Además, el municipio es donde se entretejen los nuevos mimbres de la participación política con los cuales reconstruir la gobernabilidad del próximo siglo. Ante la globalización de todos los parámetros socio-políticos emerge con fuerza la idea de aprovechar el ámbito local como instrumento para aproximar la acción de gobierno a los ciudadanos.

- Demanda de un nuevo papel de las Administraciones. La percepción que la ciudadana tiene de sus Administraciones públicas no es del todo buena. Hay una creciente desconfianza de los ciudadanos con su Administración aunque éstos no dejan de pedir que la misión fundamental de las Administraciones públicas es servir a los ciudadanos de la manera más eficaz con el uso más eficiente posible de los recursos. Para los ciudadanos éstos son los nuevos referentes que complementan el sentido tradicional de lo público.

Ante estos factores las Administraciones Públicas deben reflexionar si su identidad y sus formas de organización son las más adecuadas para responder a estas presiones sociales y politicas. Se trata de una reflexión urgente. De ella depende, ni más ni menos, la propia supervivencia de la Administración pública. Si desde el sector público no se dan las respuestas adecuadas a las nuevas preguntas de la sociedad del siglo XXI, será muy difícil aguantar las presiones de quienes atribuyen al sector público un papel meramente simbólico o residual ante la racionalidad autorreguladora atribuible a las fuerzas del mercado.

\section{Agotamiento del modelo burocrático de Administración}

Los datos de diversas encuestas sociológicas manifiestan que las Administraciones públicas no gozan de la plena confianza de los ciưdadanos. Existe una pérdida de confianza en los ciudadanos sobre el papel que puede desarrollar la Administración en el futuro. Nos encontramos en unos momentos que pueden definirse como de "crisis de expectativas en los clientes del sector público. 2 .

Los cambios y las mutaciones económicas iniciadas en los años setenta han modificado progresivamente el consenso social creado alrededor de un determinado modelo de Estado del Bienestar. Esta crisis cuestiona la racionalidad que fundamentaba el funcionamiento de la Administración pública: la organización burocrática porque es incapaz de responder a las exigencias y a las necesidades, siempre en transformación, de la nueva sociedad de la información y del conocimiento. Las corrientes políticoideológicas que, influidas por un contexto económico y social muy estable, auspiciaron un modelo de Estado de Bienestar basado en una fuerte presencia e intervención del Estado en la sociedad, creyeron que para el buen éxito de este proyecto se precisaba una importante y desarrollada Administración pública. R. Gomà y Q. BRugué dicen que "el consenso político implicó un cierto compromiso bacia la igualdad entre las personas y que tal empeño por la igualdad exigía el refuerzo de "las lógicas estandarizadoras y monopolistas, ${ }^{3}$.

Pero el consenso sobre el Estado del Bienestar se ha roto definitivamente porque la cultura organizativa propia de la "Gestión de la Estabilidad, ha sido incapaz de resolver los problemas nuevos de las sociedades modernas. De la "Gestión de la Estabilidad" hemos pasado a la "Gestión de la Incertidumbre, ambos términos propuestos por R. Gomà y Q. BRuguÉ. Estos autores contraponen la igualdad y el monopolismo propios de los entornos estables a la diferenciación y el pluralismo existentes en los entomos cambiantes de las sociedades postindustriales. De todo ello concluimos que la Administración pública diseñada para la sociedad industrial no está a la altura de los desafíos y los retos del siglo XXI. Para que la Administración pública vuelva a ser eficaz o para recuperar su credibilidad débemos reinventarla.

\section{Un nuevo consenso}

Si queremos entrar con buen pie en el siglo XXI, hay que crear un nuevo consenso social y político alrededor de las Administraciones públicas. El futuro de los servicios públicos depende de nuestra capacidad para crear un nuevo paradigma de las Administraciones públicas. Los expertos en asuntos públicos no se ponen de acuerdo en cuál debe ser este futuro, o presente inmediato, de las Administraciones públicas; ni cuáles son los caminos a emprender. Para unos se trata de reformar, en lo posible, la lógica weberiana del modelo burocrático (son los neoweberianos). Para otros se trata de construir un modelo totalmente alternativo (son los denominados postburocráticos), en este grupo se integran los patrocinadores de la Nueva Gestión Pública (NGP). Finalmente, existe una tercera corriente que patrocinan la denominada Orientación al Servicio Público (PSO, que es un acrónimo de Public Service Orientation); estos últimos, sin negar algunos de los diagnósticos o propuestas de las anteriores corrientes, les critican su falta de interés ante el déficit democrático del modelo burocrático. Para conocimiento más detallado de estos paradigmas emergentes y sus mentores sugiero consultar los estudios de Q. BRUGUÉ ${ }^{4,5}{ }^{6}{ }^{\circ}$ o de S. RiCHARDS ${ }^{7}$.

Para E. LÖFFLER los principios básicos del paradigma propuesto por los partidarios de la NPG son "orientación al cliente, 
mayor libertad en la gestión de recursos y personas, medición del rendimiento, inversión en recursos tecnológicos y bumanos $y$ receptividad ante la competencia ${ }^{8}$. Se trata de cambiar la visión, dominante actualmente en el sector público, muy escorada hacia un pensamiento legalista, por otra más preocupada por la realización práctica del que se denominan las tres E: economía, eficacia y eficiencia. Los partidarios del paradigma de la PSO son más críticos. Les disgusta el exceso de interés que la NPG presta por las cuestiones económicas y su olvido constante del déficit democrático de la burocracia weberiana. Por ello sugieren como alternativa recuperar la esencia político-administrativa de las Administraciones públicas combinando las dimensiones más instrumentales, básicamente similares a las propuestas por los partidarios del paradigma de la NPG, con la incorporación de medidas compensatorias del déficit democrático de la Administración pública tradicional.

Las reformas necesarias para transformar la gestión pública exigen un profundo cambio de mentalidad, tanto de los representantes de la gobernación como de los gestores de la Administración, que permita combinar las modernas prácticas de gestión con la necesidad de redimensionar el costo económico del sector público, la defensa de los valores centrales de los servicios públicos y la creación de un nuevo espacio de participación política alrededor del tema de la gobernación. El nuevo consenso sobre las Administraciones públicas exige tomar importantes decisiones políticas sobre diversos temas que, por su importancia estratégica, van a condicionar el modelo venidero de Administración pública del próximo milenio. Considero que estos temas son:

- ¿Qué modelo organizativo debe adoptar la nueva Administración pública para ser creíble a los ciudadanos?

- ¿Cómo centrarse en los ciudadanos y favorecer su libertad de elección?

- ¿Cómo gestionar la Administración pública?

- ¿Cómo aprovechar al máximo las potencialidades de las tecnologías de la información?

\section{Ayuntamientos receptivos}

Los países miembros de la OCDE, a finales de los años ochenta, conscientes de la crisis progresiva del modelo burocrático de Administración pública propusieron una nueva concepción de Administración pública que significaba "abandonar la noción de relación entre administrador y administrado para considerar que la Administración es un servicio cuyo cliente es el puiblico, ${ }^{9}$. De forma, quizás algo contundente, en esta frase se condensaba el nuevo enfoque que estos países querían dar al nuevo modelo de Administración pública.
Los diversos países miembros de la OCDE propusieron cambiar radicalmente la actual cultura administrativa. La Administración pública del futuro debía ser una *Administración receptivan. Los países de la OCDE propuisieron el término arecettividado porque "la Aministración-servicio, o la receptividad de la Administración lel término inglés "reponsiveness" es más activo que "receptividad", y significa "capacidad de respuesta" (a la evolución de la demanda)], es una consecuencia del funcionamiento de la Administración y, en primer lugar, una disposición de ánimo, ${ }^{10}$. Para la OCDE existen cuatro grandes ejes que dan contenido al concepto de receptividad de las Administraciones. Se considera que una Administración es receptiva cuando: es comprensible, responde a las necesidades de los ciudadanos, es accesible y fomenta la participación activa.

- Comprensible (y comprensiva). Las Administraciones públicas deben ser transparentes. Los ciudadanos deben saber cómo funciona la Administración, cuáles son sus obligaciones y también cuáles son sus responsabilidades hacia él y quiénes son sus responsables. Además, los ciudadanos han de entender la Administración, por ello su información debe ser clara. Los procedimientos deben ser más sencillos y simples. La ética debe presidir la relación de la Administración con los ciudadanos.

- Responde a las necesidades de los ciudadanos. Las Administraciones deben atender las necesidades de los ciudadanos, tanto en la acción de gobierno -cuando se diseñan las políticas públicas- como en su aplicación por medio de la Administración. Además, los ciudadanos exigen servicios adaptados a sus necesidades particulares, por ello ya no son posibles servicios de talla única. Los ciudadanos quieren que sus opiniones se tengan en cuenta.

- Accesible. Los ciudadanos exigen que, además que la Administración sea comprensible, en lo particular sea fácil de relacionarse con ella. Accesibilidad significa horarios cómodos; niveles de información y formas de comunicación. ajustadas a la comprensión de los ciudadanos y adaptación a los distintos niveles de discapacitación de los ciudadanos.

- Participación activa. La Administración debe fomentar la participación activa de los ciudadanos. Porque los ciudadanos no quieren ser receptores pasivos de los servicios públicos ni los empleados públicos quieren permanecer ajenos al proceso de transformación de las Administraciones Públicas. Éstas deben promover una mayor implicación de los usuarios de los servicios y con una mayor participación de los empleados públicos en la mejora de su prestación. 
D. SHAND y M. ARNBERG ${ }^{11}$ proponen reformular los principios de una Administración receptiva, de tal manera que algunas de las anteriores ideas podrian expresarse ahora con los siguientes términos:

- Los ciudadanos participan en las decisiones (o son consultados) sobre el nivel y el tipo de servicio a prestar.

- Se informa a los ciudadanos del nivel y del tipo de servicios que presta la Administración.

- Los ciudadanos pueden razonablemente esperar el nivel de servicio prometido.

- Los ciudadanos tienen derecho a quejarse y a ser indemnizados si el nivel de servicio obtenido no es el adecuado.

- Los organismos públicos prestadores de servicios deben fijar objetivos de calidad y dar a conocer cómo trabajan.

\section{Calidad total y receptividad}

Ante la necesidad de gestionar el cambio de orientación de las Administraciones públicas los gestores públicos buscaron qué estrategias eran las más adecuadas para conseguir los objetivos perseguidos por el modelo de Administración receptiva. Así fue cómo muchos de estos gestores descubrieron que las diversas ideas y propuestas agrupadas en torno del concepto de Calidad Total, o en sus múltiples variantes de gestión de la calidad, permitian armar un sistema de gestión pública coherente con los objetivos de hacer una Administración pública más receptiva.

La Calidad Total ha entrado de lleno en las Administraciones públicas y muy especialmente en el ámbito municipal. Los ayuntamientos están utilizando algunas de las estrategias de la gestión de la calidad para mejorar la prestación de sus servicios. El uso de las técnicas asociadas a la gestión de la calidad es "parte de la dirección general bacia donde señalan las reformas en la gestión pública que aspiran a realizar los países miembros de la OCDE, en concreto para mejorar la sensibilidad de las instituciones" "2. Este enfoque de las Administraciones públicas hacia la calidad se está convirtiendo en un aspecto fundamental para su modernización. Muchos ayuntamientos incorporan la gestión de la calidad en sus agendas públicas porque les permite emprender reformas de mayor envergadura coherentes con el empeño de crear la nueva legitimidad del sector público.

Los pioneros de la nueva reforma de la Administración pública descubrieron que la Calidad Total, además de una metodología o una serie de técnicas, es una filosofía transformadora de las organizaciones. Un estudio reciente efectuado en distin- tas Administraciones públicas revela que existen ocho grandes cuestiones comunes en todos los esfuerzos de mejora de la calidad de los servicios públicos. Quisiera hacer notar que en estas cuestiones no se mencionan aquellos aspectos más políticos que la gestión de la calidad en el ámbito público también puede ayudar a resolver. Estos elementos, ordenados según la importancia otorgada por las propias Administraciones, son:

- Voluntad de satisfacer a los ciudadanos (identificados como usuarios, clientes, parroquianos, personas interesadas - stakebolders—, etc.).

- Compromiso por un nuevo liderazgo directivo orientado a prestar servicios de calidad.

- Mayor preocupación por el empowerment ${ }^{13}$ de los empleados públicos y por su participación en la toma de decisiones.

- Mayor atención en cómo se prestan los servicios y cómo su mide su calidad.

- Simplificación de los procedimientos de trabajo (disminución de la cadena de mando, supresión de aquellos trabajos que no aportan valor añadido, menos papeleo, etc...).

- Adopción de una visión estratégica, especialmente orientada a mejorar la calidad de los servicios.

- Creación de climas laborales y organización del trabajo más motivadora para los empleados públicos.

- Adopción de sistemas de trabajo más flexibles (en la gestión de personal, sistema de compras, etc...).

Los esfuerzos realizados por varias administraciones locales de varios países para aplicar programas de calidad están dando sus frutos. Hoy existen numerosas experiencias que permiten construir una teoría propia de la gestión de la calidad en el ámbito municipal. Al hilo de estos resultados podemos proponer una lectura y una aplicación municipalista de los principios básicos de la Calidad Total. Existe el convencimiento de que la calidad en el ámbito local puede formularse en términos parecidos a los expresados por el movimiento municipalista inglés a principios de los años 90: "calidad es prestar servicios que unen los compromisos adquiridos por los políticos con las necesidades del servicio de los usuarios y de la comunidad de manera económica, efectiva, eficiente y equitativan ${ }^{14}$.

\section{Ciudadanos y clientes}

La introducción de la filosofía de la gestión de la calidad en el sector público reabrió el debate sobre si los ciudadanos de- 
berían ser considerados como clientes verdaderos de las Administraciones. En un primer momento se constató que se trataba de un problema complejo que exigía superar un primer estado de confusión, cuando no de rechazo, y que se debían considerar diversos aspectos que confluyen en este debate conscientes de que, según como se resolviese esta cuestión, se dibujaba un modelo u otro de Administración pública para el siglo próximo.

No se puede utilizar el término cliente para identificar, sin más, a todas las personas que, en cualquier situación, se relacionan con los servicios públicos. Aunque por conveniencia aceptemos utilizar el término cliente a modo de resumen, ello no debe ocultar que existen muchas tipologías y modos de relación entre los ciudadanos y las Administraciones públicas y que, en contadas ocasiones, se dan las características más definitorias de una relación cliente proveedor: la libertad de elección.

También debemos analizar si los beneficiarios de los servicios públicos comparten las mismas características que tienen los clientes en sus transacciones con las empresas privadas. Si para el sector privado es fácil identificar los clientes como aquellas personas que pagan por unos servicios; no sucede lo mismo en el ámbito público mientras no exista un uso generalizado del pago por servicios. Además, en muchas ocasiones, quienes reciben los servicios prestados por la Administración no son quienes contribuyen totalmente a su financiación; mientras que existen otros ciudadanos que, sin recibir los mismos servicios, quizás contribuyen relativamente más a su financiación.

A pesar de las importantes diferencias existentes entre los clientes del sector público y los beneficiarios del sector público, o los matices que pueden establecerse entre usuarios directos de los servicios públicos y sus contribuyentes vía impuestos, resulta útil, para los propósitos de modernización de las Administraciones, considerar como clientes de los servicios públicos aquellas personas que se benefician de los mismos. Tanto porque ellos expresan una demanda como porque se relacionan con la Administración como prestadora de servicios. Sue RICHARDS afirma que "los clientes de los servicios públicos pueden ser definidos simplemente como los receptores inmediatos de los servicios, en vez de, como ocurre en el sector privado, ser definidos como compradores (...) También puede haber una definición más amplia del cliente para incluir el concepto de ciudadano alli donde los intereses de un grupo más amplio forman parte de la transacción, ${ }^{15}$.

Las anteriores palabras de Sue RichaRDs plantean la cuestión de si los ciudadanos, en sus relaciones con la Administración, deben ser considerados meramente consumidores de los servicios públicos o deben tener otro tratamiento. Creo que corremos el peligro, cautivados por un exceso de confianza reparadora en las técnicas de gestión, de considerar al ciudadano únicamente como cliente consumidor de la Administración y que la misión de ésta sea, únicamente, atender eficaz y eficientemente, como mero administrador, sus peticiones. Hay que proponer otro punto de vista. Como muy bien dicen PrIOR, STEWART y WaLSH - los servicios públicos no son normalmente servicios individuales proveidos sobre una demanda que responde a unas necesidades, o a unas peticiones colectivas. Sirva esto no para argumentar contra la mejora del servicio para los clientes, sino para tomar conciencia que el servicio está dentro de un sistema de politica pública. En el pasado este sistema ba tendido a descuidar al cliente. Sin embargo, seria igualmente peligroso asumir que el interés público pudiera descuidar el interés por el cliente individual. En el servicio público ban de equilibrarse el interés puiblico $y$ las necesidades del usuario o del cliente ${ }^{16}$. Hay que ampliar el concepto de cliente, aunque sigamos utilizando coloquialmente este término, incorporándole la dimensión de ciudadano. Sólo así lograremos dar a este concepto una dimensión plenamente comunitaria, en lugar de lectura individualista que comporta, de entrada, el concepto cliente.

La orientación al cliente no debe diluir las responsabilidades que los cargos electos tienen en la dirección del gobierno municipal. La incorporación de la preocupación por los clientes da una nueva dimensión a la acción de gobiemo, pero jamás debe laminar la intervención de los cargos electos en la gobernación del municipio. Un ayuntamiento no es un supermercado de servicios. Los decisores políticos, en quienes descansa la gobernabilidad de las Administraciones, nunca deben perder de vista que en la prestación y recepción de los servicios públicos confluyen numerosos y variados intereses. El decisor político no puede eludir la "responsabilidad duab ${ }^{17}$ que toda acción de gobierno comporta: saber consensuar el interés individual con el interés público. Porque en el contexto municipal la responsabilidad política exige que los gobernantes definan qué es el interés común y que sean ellos quienes decidan, ante un número infinito de demandas, cuáles se atienden, qué servicios se prestan, a quién se presta y cómo se prestan. Los gobernantes actúan representando a todos los ciudadanos y éstos, como colectivo, a pesar de todos los matices, deben ser considerados, ciertamente, como clientes de las Administraciones públicas. Pues, a pesar de todos los matices que tiene el concepto, es recomendable el uso del término cliente si ello sirve para condensar simbólicamente el sentido que debe tomar la nueva modernización de lạs Administraciones públicas.

\section{Propuesta de un sistema de calidad municipal}

La experiencia del sector privado ha animado a algunos organismos, cuya misión es orientar a quienes quieren implantar 
la gestión de la calidad, a difundir modelos de gestión de la calidad que parten de la concepción de la calidad como sistema. La gestión de la calidad én el ámbito municipal debe considerarse y tratarse como un sistema: el Sistema de Calidad Municipal. Este sistema, de acuerdo con lo establecido por la norma ISO 9004 consta de "una estructura organizativa, las responsabilidades, los procedimientos, los procesos y los recursos necesarios para llevar a cabo la gestión de la calidad.

El sistema de calidad está compuesto de varios subsistemas que surgen de los distintos niveles de decisión y de actuación presentes en el entorno municipal. Cada uno de estos sistemas influye en la obtención de la calidad total del ayuntamiento.

- Calidad en la dirección. Los órganos de gobierno del ayuntamiento deben establecer con claridad cuál es la visión y las misiones que orientarán tanto las prestaciones de servicios obligatorias, como aquellas actuaciones que se integren en la agenda política. Quienes tengan la responsabilidad de la dirección municipal deberán incorporar el punto de vista del ciudadano en el momento de su toma de decisiones.

- Calidad en los procedimientos. Se trata de gestionar los procedimientos más adecuados para conseguir los objetivos y resultados propuestos, especialmente los relacionados con la satisfacción de los ciudadanos, y procurar que ello se consiga de la forma más transparente, eficaz y eficiente.

- Calidad en las relaciones internas. Esta parte del subsistema debe procurar que en las múltiples relaciones internas que se dan en la organización municipal para la prestación de servicios a los ciudadanos se apliquen las exigencias propias de una relación cliente-proveedor interno.

- Calidad en las relaciones con los proveedores. Asegurar que el sistema de proveedores y las condiciones que regulan las compras de bienes y servicios del ayuntamiento sean las más idóneas para garantizar la eficacia y la eficiencia de los servicios al ciudadano, así como un uso eficiente de los recursos públicos.

- Calidad en las relaciones con el entorno. Se trata de conseguir que los diferentes niveles relacionales externos del ayuntamiento, así como sus influencias sobre el entorno, en su sentido más amplio, incluso en la dimensión medioambiental, estén presididas por los criterios globales de calidad.

- Calidad en la prestación de los servicios al ciudadano. Esta parte del sistema se ocupa del correcto diseño de la prestación de los servicios a los ciudadanos. Es la parte final de todo el proceso de gestión de la calidad municipal de la cual depende que el ciudadano quede satisfecho de la calidad de los servicios prestados por el ayuntamiento.

\section{Organización del gobierno, estructura de la organización}

Uno de los retos para hacer una Administración más atenta y receptiva es abandonar la idea de que lo local es una simple prolongación, en algunas ocasiones cuasi subordinación, de las otras Administraciones; para asumir que el ámbito local es un ámbito político de gobierno. Quizás para el período 1999-2003 se podría asumir como slogan del mundo local la siguiente afirmación: "de la administración local al gobierno locab. Con esta afirmación nos situaríamos frente a uno de los retos más importantes del municipalismo hoy: la gobernabilidad de las corporaciones locales.

La implantación de la gestión de la calidad necesita de unos determinados modelos organizativos, estilos de dirección y de gestión. Existen unas culturas organizativas que favorecen más que otras el desarrollo de la gestión de la calidad en las corporaciones locales y hay otras que lo entorpecen o, incluso, lo impiden. A grandes rasgos proponemos los siguientes referentes organizativos a tener en cuenta por quienes estén dispuestos a aplicar la calidad en el ámbito municipal.

- Separación del ámbito de dirección politica de la esfera de gestión operativa

La gestión de la calidad exige repensar las funciones y los roles que deben desarrollar quienes, dentro del ayuntamiento, asumen la esfera directiva política o el ámbito gerencial. Se trata de que los cargos electos locales ejerzan realmente la dirección política en la acción de gobierno de los ayuntamientos. Ello exige adoptar una estructura organizativa nueva que deslinde claramente la dirección política de la gestión directiva.

Se trata de reservar para la dirección política de los ayuntamientos la creación de un marco global de referencia a partir del propio programa de gobierno. Mientras la dirección política del ayuntamiento es la responsable de fijar la dirección a tomar, el ámbito gestor debe saber adoptar las medidas y actuaciones necesarias para alcanzar los resultados previstos. La gestión del ayuntamiento, que según sus características puede estar bajo la responsabilidad de un gerente o figura similar, debe articular la prestación de servicios y todas aquellas actividades que permitan obtener los resultados fijados por la direc- 
ción política. En aquellos casos que no sea posible asumir la figura gerencial, sí que debe quedar claro la existencia de ámbitos de actuación diferenciados para los cargos electos, por un lado, y el resto de la organización municipal, por el otro.

\section{- $\quad$ Liderazgo participativo}

La gestión de la calidad comporta la modificación de los roles clásicos a desarrollar por los directivos y los empleados públicos. La calidad en los servicios municipales únicamente podrá lograrse a partir del compromiso efectivo de los trabajadores del ayuntamiento. Ello únicamente será posible si desde la dirección política y desde la responsabilidad gerencial se ejerce un verdadero liderazgo participativo.

Como alternativa a una concepción taylorista del trabajo y una organización burocrática de la Administración, la filosofía de la gestión de la calidad debe proponer una nueva estructura organizativa. Ésta debe basarse en el desarrollo del conocimiento existente dentro de la organización municipal y que exige, además, que los directivos desarrollen un liderazgo participativo basado en una visión compartida por todos los empleados públicos.

Las consecuencias de este enfoque en la Administración local son muy diversas. En primer lugar, el desarrollo de una cultura participativa debe propiciar un cambio en la propia concepción de la organización municipal. Por ejemplo, la unidad básica de la organización no debería ser tanto el puesto de trabajo, sino el equipo. Unidad operativa responsable de lograr los resultados fijados por la organización.

En segundo lugar, este enfoque modifica el rol del directivo público local. Éstos ahora, fundamentalmente, son mediadores entre las demandas de los ciudadanos y los grupos de empleados que deben atenderlas aplicando al máximo su creatividad. Además, los directivos locales deben desarrollar un estilo de gestión más integrador, cooperador y participativo. Se trata, en definitiva, que los directivos públicos sean capaces de aprovechar y aplicar el saber de sus colaboradores y liderar equipos de trabajo.

\section{- Estructuras flexibles y adaptables}

La gestión de la calidad exige desarrollar una nueva concepción del ayuntamiento como organización. La rapidez de las transformaciones de la sociedad y la propia organización del saber dentro de las corporaciones locales ponen en evidencia la poca utilidad que tienen los modelos tayloristas y burocráticos de organización municipal. La orientación hacia el ciudadano de la Administración local exige un nuevo modelo de organización muy diferente al actual.

Se trata de promover un modelo organizativo del ayuntamiento que sea fácilmente adaptable y flexible a los cambios rápidos del entorno. Para ello, más que pensar en agrupar los trabajadores en unidades funcionales, se trata de organizarlos por equipos y redes flexibles que se modifican y transforman, de acuerdo a las necesidades y demandas del momento. En este nueva propuesta de diseño organizativo es relevante descentralizar la toma de decisiones y aumentar la autonomía de gestión hacia los niveles más próximos a los ciudadanos.

Al final de este proceso, las características de los ayuntamientos son: organizaciones bastante planas, con pocos niveles jerárquicos, con pocas reglas y normas, -las imprescindibles-, organizados en pequeñas unidades descentralizadas, sometidas a permanente revisión, basadas en las personas, donde cada trabajo sea una pequeña misión, un reto y un motivo de aprendizaje, y orientadas a la rápida circulación de ideas y de información.

\section{- Obtención de resultados}

La gestión de la calidad sólo será posible si la organización municipal desarrolla un nuevo modelo de gestión pública orientado a la obtención de resultados. Tal como dice la OCDE, en los últimos años ha surgido un nuevo modelo de la gestión pública basado en una "orientación hacia los resultados, en términos de eficiencia, de eficacia y de calidad del servicio ${ }^{18}$. La orientación hacia los resultados es fundamental para el proceso de restructuración organizativa de las Administraciones locales. Una mayor descentralización de funciones hacia las unidades operativas y sus directivos, tal como se ha propuesto anteriormente, exige un mayor control de la dirección política sobre los resultados.

Esta orientación hacia los resultados permite desarrollar nuevos grados de responsabilidad dentro del ayuntamiento. Para los empleados públicos y los gestores de los recursos humanos la existencia de resultados de gestión medibles puede permitir evaluar el grado de desempeño y vincular la productividad a los resultados alcanzados. La existencia de resultados permite también resituar las relaciones que establece un ayuntamiento con las empresas externas prestadoras de servicios municipales. Todos estos aspectos obligan a repensar seriamente el sistema de recursos humanos de los ayuntamientos, tal como se aborda en el siguiente apartado. 


\section{- Desarrollo de los recursos bumanos}

Los recursos humanos son una de las piezas clave para la implantación de la calidad en los ayuntamientos. La aplicación de la gestión de la calidad no será posible sin una revisión de las políticas de recursos humanos aplicadas en la mayoría de ayuntamientos. El reto estratégico para la Administración local es pasar de la administración de personal a la gestión de recursos humanos.

La responsabilidad de la dirección de personal ya no debe ser competencia exclusiva de unos departamentos centralizados. El enfoque de la gestión de la calidad exige aumentar la responsabilidad de los directivos locales sobre su personal. Ellos deberían poseer buena parte de las competencias ahora en manos de las unidades centrales de personal.

Hay que entender la dirección de los recursos humanos como un verdadero sistema formado por distintos subsistemas todos entrelazados y vinculados a la política general del ayuntamiento. Parte de algunos de estos subsistemas, hasta ahora competencias de las unidades de personal, deberían transferirse rápidamente a las unidades operativas.

El enfoque hacia la calidad de los servicios comporta una transformación en algunas de las categorías profesionales de los ayuntamientos y la reasignación de los recursos humanos. Resulta especialmente recomendable fomentar el desarrollo de capacitaciones polivalentes. Este proceso debe realizarse planificadamente y confiando en la formación como palanca de cambio de este proceso de modernización. El proyecto formativo debe estar, fundamentalmente, enraizado en el proyecto de cambio organizativo del ayuntamiento.

\section{- Simplificación de la Administración}

Durante los últimos años las Administraciones públicas han ido creciendo desmesuradamente $y$, de manera especial, el conjunto de normas que regulan sus relaciones con los ciudadanos, empresas y entidades. Alguien calificado, acertadamente, esta situación de "voracidad reglamentista. A pesar de existir una clara evidencia de los costos negativos indirectos de la reglamentación sobre el desarrollo económico de un país, no existen demasiadas evidencias de una disminución de la presión social a favor de una mayor reglamentación.

La existencia de un contexto profusamente reglamentista en las Administraciones públicas atenúa el grado de responsabilidad de los distintos actores implicados. Se trata de poner coto a la "desbordante cascada reglamentista, y racionalizando y reduciendo el inmenso conjun- to de normas emanadas en los uiltimos decenios, desregulando basta donde sea preciso aquellos sectores y actividades" ${ }^{19}$. Hay que reducir notablemente el volumen de normas y reglamentos que enmarañan las Administraciones públicas en general y que repercuten sobre la capacidad de actuación de los ayuntamientos. Además, éstos deben liberarse de la inercia de crear nuevos desarrollos normativos sobre los ya existentes. La propuesta es avanzar hacia un proceso de desreglamentación y un aumento de transparencia y claridad en la actuación pública. Se trata de liberar al político local del máximo número de trabas que impidan tomar decisiones o ser un rehén de los expertos conocedores de las lógicas reglamentistas.

\section{- Nueva Cultura organizativa}

La consolidación de ayuntamientos receptivos a las necesidades de los ciudadanos exige abandonar una cultura organizativa burocrática centrada en el poder y adoptar una orientación al servicio y la cooperación. Para poder desarrollar los proyectos de calidad de servicio hay que transformar determinadas creencias, hábitos y comportamientos, algunos de arraigo secular, y que tienen su origen en la concepción burocrática de las Administraciones públicas. En este sentido, este cambio cultural está estrechamente relacionado con una mayor incorporación de la mujer en los puestos claves de decisión y gestión de la Administración local. La presencia de un mayor número de mujeres en estos puestos de responsabilidad, además de normalizar una situación, permitirá modificar los patrones culturales de dominación y poder presentes en la mayoría de organizaciones. La orientación al servicio y la cultura de la cooperación exigen desarrollar nuevas sensibilidades muy diferentes a las hasta ahora dominantes en el ámbito público. Estos nuevos parámetros culturales serán posibles, tanto por el cambio de mentalidad de quienes ya estén asumiendo responsabilidades públicas, como por la incorporación de personas que, sin intentar reproducir las actualmente existentes, aporten otras visiones y lecturas de aspectos tan dispares como son las relaciones humanas o el uso del tiempo.

El desarrollo de la calidad en cualquier organización, y los ayuntamientos no son una excepción, adescansa sobre unas estructuras profundas de creencias, visiones y valores bumanos, algunos muy antiguos y otros mucho más recientes ${ }^{20}$ que, a modo de estratos, van sedimentándose sobre el conjunto de elementos que integran la cultura organizativa de los ayuntamientos. En la nueva cultura del servicio público tiene mucha importancia el concepto de empowerment de los emplea- 
dos públicos como complemento necesario al proceso de descentralización y delegación del control. Se trata de conferir, y formar para ello, la autoridad a las personas responsables de desarrollar y aplicar la calidad dentro del ayuntamiento.

La transformación de la cultura burocrática de los ayuntamientos está relacionada, de alguna manera, con la modificación de la propia idea de cambio que se tiene. No se trata tanto de impulsar espectaculares procesos de cambio cultural. Como dice P. DRUCKER, en muchos casos el cambio deseado se consigue abaciendo sistemáticamente algo que todos sabian desde tiempo atrás que se debia bacer ... aunque sólo en unos pocos casos excepcionales se babia practicado ${ }^{21}$. Con una visión prágmática diríamos que si una corporación local quiere introducir la cultura del servicio público orientada hacia el ciudadano, tanto ha de modificar aquellos hábitos y comportamientos que impiden ir en esta dirección; como reforzar y potenciar aquellos hábitos y comportamientos de la corporación que consolidan la nueva orientación.

\section{Estrategias para implantar la calidad}

No creo que exista una estrategia general que pueda recomendarse como camino mágico hacia la calidad en la Administración local. Más bien pienso que habrá que utilizar múltiples estrategias adaptadas a las diferentes realidades de las Administraciones locales. Con todo, y sabiendo que las siguientes propuestas deben estar permanentemente sometidas a escrutinio, sugiero una serie de recomendaciones que trazan una posible vía metodológica para implantar la gestión de la calidad en un ayuntamiento.

\section{Primera recomendación: planificar la calidad}

La calidad en una Administración local no se alcanza por esfuerzos espontáneos, sino por la acción planificada efectuada desde posiciones de gobierno. Recrear la Administración en clave de calidad necesita. ser un objetivo del gobierno municipal. Para ello el equipo político municipal debe comprender que repensar la Administración pública en clave de calidad es algo más que cuatro actuaciones de propaganda, se trata de consolidar un sistema de dirección y gestión cruzados por los conceptos de calidad.

\section{Segunda recomendación: crear una estructura impulsora}

La segunda recomendación es que el equipo de gobierno cree y lidere un órgano impuisor de todo el proceso de la calidad dentro del ayuntamiento. Su composición puede ser varia$\mathrm{da}$, pero la organización debe percibir que se trata de un grupo humano investido de autoridad y con autoridad reconocida para pilotar el proceso. Este grupo impulsor debe recibir una formación específica. Más que someter al grupo impulsor a un baño de conceptos, es mejor que el grupo aprenda qué es calidad construyendo el propio armazón del sistema de calidad del ayuntamiento. Para ello creo, sinceramente, que el modelo de la Fundación Europea para la Calidad (EFQM), que será utilizado en la siguiente fase, ofrece muchas oportunidades para combinar el aprendizaje de la calidad con la creación del propio sistema.

\section{Tercera recomendación: diagnosticar el estado de la calidad}

El paso siguiente consiste en saber en qué estado se encuentra el ayuntamiento y cómo perciben los ciudadanos que está. Para ello sugiero que el grupo impulsor utilice el modelo de diagnóstico de la EFQM, aunque este modelo reclama una adaptación más real a la Administración pública local. También pueden utilizarse otros instrumentos de autoevaluación, por ejemplo los criterios de calidad formulados por el Instituto Nacional de Calidad de Canadá ${ }^{22}$ también pueden ser útiles para este propósito. La autoevaluación permite obtener una visión, a modo de foto fija; de como la organización dice que se encuentra. El paso siguiente consiste en salir fuera de la organización y saber qué percepción tienen los ciudadanos de la organización municipal. Para ello el grupo impulsor debe aprender a manejar cuestionarios del tipo Servqual o calidad de servicios ${ }^{23}$. Puede ser útil que el grupo impulsor utilice otros mecanismos de sondeo de opinión o aprenda a aprovechar las múltiples fuentes de información existente ya en un ayuntamiento para releer estos datos desde la perspectiva de la calidad.

Algunos ayuntamientos han empleado técnicas cualitativas para conocer la opinión de los ciudadanos. Técnicas del tipo Focus Group o de "Grupo Nominal" son muy útiles para conocer la percepción cualificada del ciudadano. La consulta a los ciudadanos es esencial en esta nueva etapa de la gestión municipal. La consulta y la participación de los ciudadanos son una exigencia de la calidad de los servicios. Los beneficios de la consulta parecen superiores a no hacerlo. Finalmente, como complemento a estas primeras fases orientadas al diagnóstico de la organización, el grupo impulsor puede recabar información de otros municipios más experimentados en la implantación del sistema de calidad o que tiene institucionalizado un sistema de 
gestión por indicadores. Se trata de realizar un benchmarking institucional no competitivo, más bien cooperativo.

Hasta aquí lo que podríamos considerar las fases en las cuales el equipo de gobierno, primero, y el grupo impulsor, después, sitúan los alcances de la calidad dentro del ayuntamiento y evalúan el grado de la calidad municipal. Como resultado de este proceso se obtiene el diagnóstico de calidad del ayuntamiento. Las actividades de las fases siguientes permiten construir propiamente la estrategia para orientar la organización municipal hacia la calidad.

\section{Cuarta recomendación: hacer participar a los trabajadores en la mejora de la calidad}

Con los datos proporcionados en la fase de diagnóstico el equipo impulsor de la calidad puede desplegar la calidad en los diferentes niveles de la organización municipal para que llegue a todos sus intersticios. Es una buena ocasión para promover iniciativas de gestión que aúnan la prestación de servicios de calidad a los ciudadanos y la movilización de la inteligencia, la creatividad, la innovación y el compromiso de los empleados públicos en la mejora de los servicios públicos. En la Administración pública la participación de sus trabajadores es indispensable para la superación de las trabas burocráticas y la orientación de los servicios hacia los ciudadanos. La calidad en los servicios municipales únicamente podrá lograrse a partir del compromiso efectivo de los empleados públicos. Sin participación no hay oportunidades para la calidad.

Algunas Administraciones locales han desarrollado con éxito estrategias de empowerment de sus recursos humanos. Del análisis de estas experiencias se deduce que el mejor camino para impulsar el empowerment es la creación de équipos de mejora de los servicios. Con ello se crea un ámbito en el cual los trabajadores desarrollan y aplican su creatividad e inteligencia en la resolución de problemas que afectan a la calidad de los servicios prestados a los ciudadanos : Es aconsejable constituir equipos de mejora alrededor de las dificultades o errores detectados en la fase de diagnóstico. El objetivo de esta fase es introducir en la organización municipal la práctica de trabajar en grupos de mejora de la calidad. A medida que los equipos de mejora realizan su labor el equipo impulsor de la calidad deberá velar por la implantación de las soluciones propuestas.

\section{Quinta recomendación: medir la calidad}

El grupo impulsor de la calidad debe crear un sistema de información sobre la gestión de la calidad con los correspondientes indicadores de calidad. También en esta fase el grupo impulsor debe crear el sistema de recabar periódicamente la opinión de los ciudadanos para poder medir el nivel de calidad de los servicios municipales. Para mejorar la calidad hay que comparar $y$ para comparar hay que medir.

El grupo impulsor deberá estimular que cada servicio municipal establezca los correspondientes indicadores de calidad. Los indicadores de calidad pueden referirse tanto al proceso de producción del servicio como al propio resultado del servicio ó la satisfacción que éste produce a los ciudadanos. De esta manera el sistema de indicadores de calidad puede articularse en tres niveles:

- Indicadores de calidad del proceso. Este grupo de indicadores miden la calidad de los procesos que intervienen en la producción de los servicios municipales.

- Indicadores de la calidad del servicio. Este tipo de indi"cadores evalúan si el servicio ha sido prestado con conformidad a unos estándares de calidad fijados de antemano.

- Indicadores de satisfacción. Son los indicadores que miden la calidad externa del servicio o el grado de satisfacción de los usuarios.

\section{Sexta recomendación: participación de los ciudadanos}

Algunas de las iniciativas de calidad de servicios emprendidas por las distintas Administraciones públicas replantean ciertos aspectos de las relaciones entre el Estado y los ciudadanos. Un factor de éxito para la consolidación del nuevo paradigma legitimador de la nueva Administración pública es el logro de nuevas cotas de participación ciudadana, tanto en la definición como en la gestión de los servicios públicos. Se trata de incorporar el punto de vista del ciudadano tanto durante la fase de la planificación de las políticas públicas como en la ejecución de las mismas a través de la acción de gobierno. Los esfuerzos de renovación del gobierno local realizados por el nuevo laborismo de Tony Blair se basan, precisamente, en un aumento de los canales participativos de los ciudadanos y la mejora de la calidad de los servicios ${ }^{24}$.

Los ayuntamientos deben encontrar nuevas e imaginativas fórmulas de participación que aumenten su permeabilidad a la cooperación y colaboración mutua con los ciudadanos. Son atractivas las iniciativas emprendidas por algunos ayuntamientos de imaginar nuevos cauces a la participación ciudadana. Actualmente se están experimentando nuevos canales participativos que permitan aumentar la "responsabilidad participativa de los ciudadanos en la toma de decisiones en cada uno de los niveles de la Administración. Algunas de estas experiencias aprovechan los 
recursos telemáticos, para crear "espacios puiblicos virtuales desde los cuales profundizar y propagar los valores de la democracia.

Otro aspecto a considerar, estrechamente relacionado con lo anterior, es que los ayuntamientos, al ser las Administraciones más próximas a los ciudadanos son quienes mejor podrán desarrollar plenamente las propuestas de nueva participación política. Para ello los municipios deben reclamar a otros niveles de la Administración aquellas competencias que mejor permitan a los ciudadanos retomar y ejercer sus responsabilidades políticas y sociales. Se trata de dar claridad al embrollo competencial entre Administraciones. Sobre esta cuestión es interesante las propuestas del informe anual de la OCDE (Organización para la Cooperación y Desarrollo Económico) sobre la "Evolución de la gestión puiblica $1995^{25}$. En este informe se destaca la tendencia de muchos gobiernos de otorgar más responsabilidad y autonomía a los niveles inferiores de la Administración para garantizar una prestación más receptiva y eficiente de los servicios públicos. La OCDE apuesta por la descentralización hacia los niveles inferiores de gobierno. Para ello sugiere fortalecer estos niveles y promover una mayor y decidida descentralización de responsabilidades realizando, si es preciso, reformas estructurales. La propuesta municipalista de un Pacto Local iría en este sentido.

\section{Séptima recomendación: desarrollar Cartas de Servicios}

Un aspecto clave del compromiso de la Administración local con los ciudadanos es el grado de fiabilidad que éstos puedan conceder a las propuestas modernizadoras del sector público. Varias Administraciones públicas han empezado a publicar Cartas de Servicios. La confección y publicación de "Cartas de los Servicios aporta tangibilidad a las ideas que subyacen en las propuestas modernizadoras de la Administración local y permite establecer un nuevo consenso Administración-ciudadano que aporta credibilidad al proceso de modernización de las corporaciones locales. Las cartas permiten establecer un nuevo acuerdo alrededor de los derechos y deberes, tanto de la Administración como de los ciudadanos y permite recuperar la confianza de éstos con los primeros.

Las Cartas de Servicios son declaraciones de los compromisos que toma un ayuntamiento con los ciudadanos. Las Cartas de Servicios deberían explicar - por cada servicio municipal-, en primer lugar, qué nivel de calidad deben esperar los ciudadanos; a continuación contar lo que se va hacer para obtener esta calidad y, finalmente, explicar a los ciudadanos cómo transmitir sus quejas y sugerencias, en el caso que crean que la Administración no ha actuado adecuadamente de acuerdo con los indicadores establecidos y, en el caso que considere que esta actuación haya lesionado intereses, qué reparación recibirá; finalmente las
Cartas de Servicios deberían explicar cómo se evaluará la calidad. La confección de las Cartas de Servicios es un buen momento para desarrollar una amplia dinámica participativa de los ciudadanos.

\section{Octava recomendación: crear un sistema de sugerencias y quejas}

La existencia de un sistema reglado de sugerencias y quejas proporciona una valiosa información que permite a los responsables municipales saber cuál es la calidad de los servicios prestados por el ayuntamiento. Los ayuntamientos deben gestionar las sugerencias y las quejas sin complejos y jamás desde posiciones o actitudes defensivas. El sistema de sugerencias y quejas debe permitir a la organización municipal aprender de las quejas. Las quejas han de entenderse como una oportunidad para mejorar los servicios públicos locales porque los ciudadanos se quejan cuando los servicios recibidos no satisfacen sus expectativas.

\section{Novena recomendación: comunicar la calidad}

Una vez finalizada la extensión de la calidad dentro del ayuntamiento y recogidos los primeros resultados de mejora, el grupo impulsor puede iniciar la fase de difusión de la calidad. En esta fase se pretende que la organización conozca a fondo los pilares fundamentales del sistema de calidad del ayuntamiento y cada una de los empleados municipales sepa cuál será su papel en el mismo. Se trata de realizar una buena campaña de difusión de los objetivos perseguidos con la implantación del sistema de calidad, para ello el ayuntamiento debe desarrollar una campaña de marketing interno.

En esta fase, el grupo impulsor debe promover la creación de un ámbito de participación específico de los empleados públicos a través de un sistema de recogida de ideas de mejora de la calidad. Además, el grupo impulsor deberá decidir cómo motivar a los empleados para que participen, cómo se escogen y se hacen realidad sus propuestas de mejora y qué sistema de recompensas e incentivos se aplica en el caso de que las propuestas logren mejoras de calidad.

\section{Décima recomendación: documentar la mejora de la calidad}

Después de las fases anteriores es el momento de desarrollar normas que permitan asegurar la calidad de acuerdo con las propuestas operativas propuestas por los equipos de mejora. El aseguramiento de la calidad es un pilar fundamental de cualquier estrategia de calidad. El aseguramiento de la calidad se sustenta en la idea básica de que, en la gestión de la calidad, 
más vale prevenir el error que corregirlo. En una organización compleja, como es un ayuntamiento, este esfuerzo de formalización, realizado desde la óptica de la búsqueda de la calidad en los servicios prestados a los ciudadanos, se sintetiza en un elemento tangible como es un Manual de Calidad. En este manual se deben establecen las normas que deben seguir los procedimientos o las actividades a desarrollar y las competencias a aplicar para conseguir los niveles de calidad deseados por la organización. De alguna manera en este manual se sintetizan muchos de los aspectos abordados en los apartados anteriores.

\section{Undécima recomendación: evaluar la calidad}

Al final de todo el proceso el grupo impulsor debe analizar lo conseguido y comprobar el grado de calidad alcanzado. Para ello el grupo impulsor puede utilizar las mismas herramientas que ha empleado para diagnosticar la calidad. La mejor de todas las evaluaciones posibles es preguntar directamente a los ciudadanos sobre la calidad de los servicios prestados por el ayuntamiento.

\section{Duodécima recomendación: tener proveedores de calidad}

En la gestión de la calidad la relación "cliente-proveedor" es un elemento clave. Se trata de introducir una nueva dinámica que supere unas relaciones presididas, en muchas ocasiones, por la desconfianza y la prevención. La relación «cliente-proveedor introduce la perspectiva de la cooperación entre el interior y el entorno de una organización. Una empresa sólo podrá prestar servicios de calidad si sus proveedores le incorporan productos o servicios de calidad. La Calidad Total ha permitido establecer relaciones de asociación entre clientes y proveedores basada en el diálogo y la cooperación. Esta visión, que ha provocado un vuelco en las relaciones de las empresas con sus proveedores, es válida también en el campo de las Administraciones públicas.

A medida que en la Administración pública se intensifica la externalización de servicios las relaciones con los proveedores resultan claves para prestar servicios de calidad. Sin embargo, no se trata de una cuestión sencilla de resolver. El actual marco jurídico regulador del proceso de contratación pública limita, en buena parte, las posibilidades de hacer una gestión de proveedores con criterios de calidad. No obstante, los gestores públicos deben utilizar todas las posibilidades que el marco legal ofrece para desarrollar políticas de contratación de servicios orientadas a garantizar la calidad de los mismos.

Espero que todas estas recomendaciones sean útiles al lector. Muchos ayuntamientos ya han empezado a andar el camino de la calidad. Se trata de ir incorporando nuevas experiencias que permitan ampliar el conocimiento colectivo. Deseo haber contribuido, de alguna manera, a este empeño.

\footnotetext{
Jefe del Servicio de Formación Local. Diputación de Barcelona.

${ }^{1}$ Este texto es el resumen de una ponencia con el mismo título. Ambos documentos son consultables en el apartado de publicaciones del Servicio de Formación Local en la página web de la Diputación de Barcelona www.diba.es.

? KPGM Peat Marwick LLAP., Organizations Serving the Public. Transforming to the 21st Century, 1997.

${ }^{3}$ R. GoMÀ y Q. BRuguÉ, Pluralisme i flexibilitat en la prestació de serveis municipals. Institut de Ciències Polítiques de Barcelona, Barcelona, 1993, pp. 4 y ss.

${ }^{4} \mathrm{Q}$. BRuGute, sa dimensión democrática de la nueva gestión pública. GAPP n. ${ }^{\circ}$ 5-6, 1996.

5 Q. BRugut, -Gestió pública i democràcia: de l'administració del vídeo a l'administració del xip. Perspectiva $n . \stackrel{\circ}{8}$, Servei de Formació Local, Diputació de Barcelona, 1998.

${ }^{6}$ Q. BRugutí; M. Amorós y R. GOMÀ, sLa Administración Pública y sus clientes: ¿Moda organizativa u opción ideológica? GAPP n.. 1, Madrid, 1994.

' $\mathrm{S}$. RICHARDS, El paradigma del cliente en la gestión pública, GAPP n.ำ 1, Madrid, 1994.

${ }^{8}$ E. LOOFFLR, -La modernización del sector público desde una perspectiva comparativa: conceptos y métodos para evaluar y premiar la calidad en el sector público en los países de la OCDE. Documentos INAP n.- 8, Madrid, 1996, pp. 8 y 9.

9 La Administración al servicio del público. OCDE, Madrid, 1988, p. 19.

"Ocive, op.cit., p. 19.
}

"D. Shand y M. ARNBERG, L'administració receptiva al públic. Papers de Formació n.. 28, Servei de Formació Local, Diputació de Barcelona, 1996.

12. Iniciatives de qualitat en el serveis als països membres de l'OCDE. Papers de Formació n.. 41, Servei de Formació Local, Diputació de Barcelona, 1997.

13. Con el término empowerment los autores anglosajones se refieren a la relación existente entre la motivación de las personas y el nivel de participación que se les otorga. A mayor participación se corresponde una mayor motivación y un mayor compromiso. Este término engloba conceptos como delegar, dar autonomía para estar más preparados, tener mayor responsabilidad y mayor capacidad de intervención en la toma de decisiones.

14 Citizens and Local Democracy, editado por The Local Government Management Board, Abril, 1993, p. 8.

${ }^{15}$ S. RICHARDS, El paradigma del cliente en la gestión públicas, GAPP n.ำ 1, Madrid, 1994.

16 D. Prior; J. StewarT y K. WaLSH, sIs the Citizen's Charter a Charter for Citizens? The Belgrave Papers n..$^{9}$, The Local Government Management Board, Luton, 1993. p. 31.

${ }^{17}$ D. OSBORNe y P. PLASTRIK, La reducción de la burocracia. Cinco estrategias para reinventar el gobierno. Paidós , Barcelona, 1998, p. 228.

18 La trasnformación de la gestión pública. Las reformas en los países de la OCDE. Ministerio de Administraciones Públicas, Madrid, 1997. 
19 J.M. Canaies Aliende y J.M. Rodríguez Álvarez, en la Introducción, a La trasnformación de la gestión priblica. Las reformas en los países de la OCDE Ministerio de Administraciones Públicas, Madrid, 1997.

3) C. FERRAI y F.D. BARReTt, El mundo de la calidad total en la empresa (II). La Gaceta de los Negocios. Profesionales, 6 de junio de 1992.

21 P.F. Drucker, La sociedad postcapitalista. Apóstrofe, Barcelona, 1993, p. 186.

" The Canadian Quality Criteria. National Quality Institute, Ontario, 1997.
3 V.A. ZetTHAMl; A. PARASURAMAn y L.L. BERRY, Calidad total en la gestión de servicios. Díaz de Santos, Madrid, 1993.

24 Modermising local government. Renewal of local democratic government. Gobiemo Británico, 1998, Documento de Internet.

5 OCDE, Informe sobre la evolución de la gestión puiblica. Actualización de $1995 . \mathrm{Pa}$ rís, 1996, Diputació de Barcelona, 1996. 

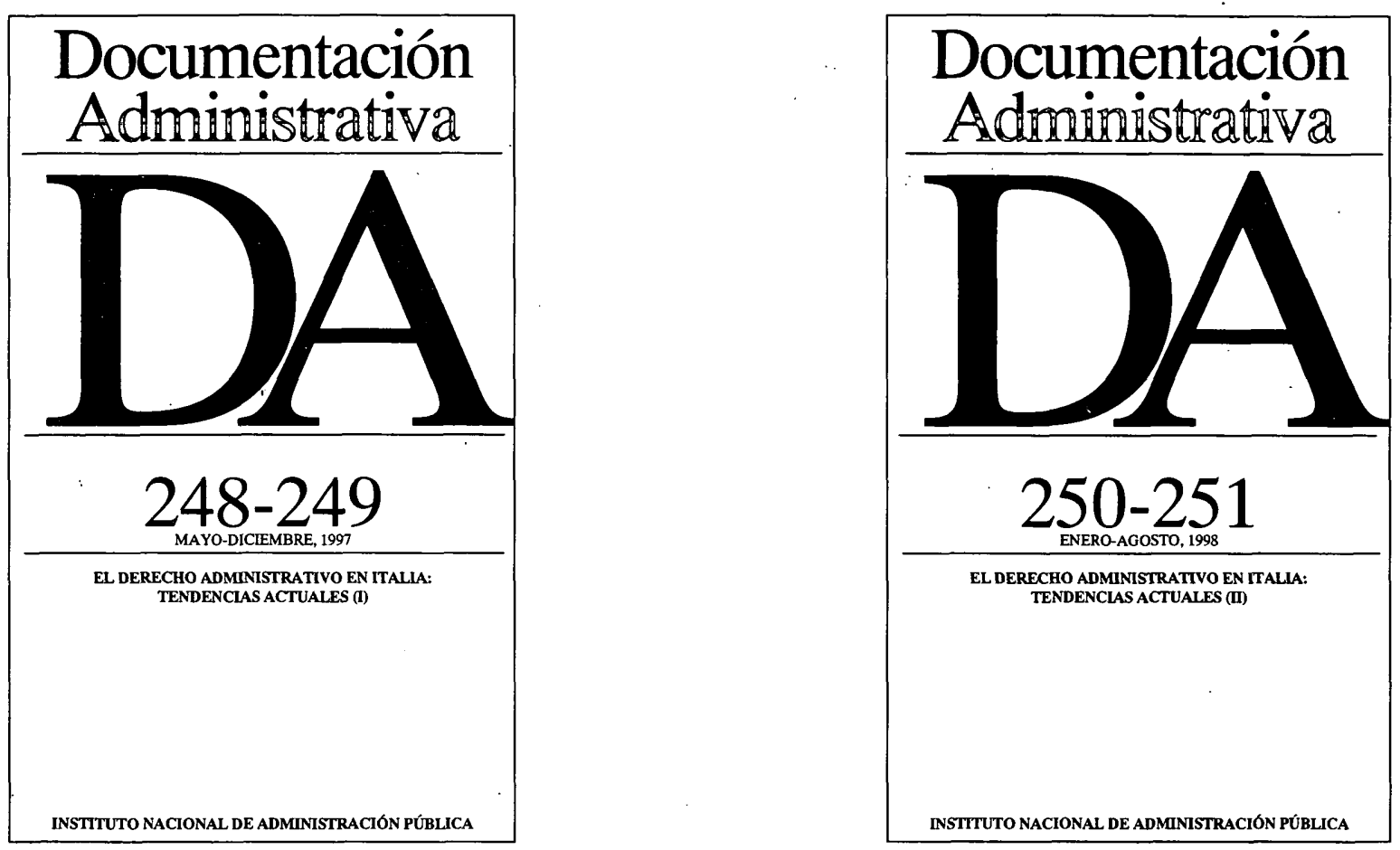

Publicación cuatrimestral del Instituto Nacional de Administración Pública, especializada en Derecho Administrativo y Organización y Gestión de las Administraciones Públicas.

Aparecida en 1958, la característica más destacada de su actual etapa es la dedicación monográfica de cada número a una cuestión específica, que se analiza desde diferentes puntos de vista por acreditadas firmas de España y otros países.

\section{CONSEJO DE REDACCIÓN}

Presidente: Enrique Álvarez Conde. Vocales: José Javier Abad Pérez, Óscar Alzaga Villamil, Manuel Aragón Reyes, Enrique Argullol Murgadas, Gaspar Ariño Ortiz, Miguel Beltrán Villalva, Andrés de Blas Guerrero, José Manuel Castells Arteche, Iñigo Cavero Lataillade, Rafael Gómez-Ferrer Morant, Francisco González Navarro, Jesús González Pérez, Luis Morell Ocaña, Sebastián Martín-Retortillo Baquer, José Ramón Parada Vázquez, Eduardo Roca Roca, Ángel Rodríguez García, Juan Alfonso Santamaría Pastor, Gumersindo Trujillo Fernández.

\section{Director}

Luciano Parejo Alfonso

\section{Secretario}

\section{Edita:}

Jesús Prieto de Pedro

MINISTERIO DE ADMINISTRACIONES PÚBLICAS

Instituto Nacional de Administración Pública

ISSN: 0012-4494

NIPO: $329-97-004-5$

Depósito legal: M. $581-1958$

Imprime: Solana e Hijos, A.G., S.A.

San Alfonso, 26. 28917 Madrid

\section{Precios:}

\section{Suscripciones y Administración:}

Instituto Nacional de Administración Pública Publicaciones Periódicas Atocha, 106. 28012 Madrid

Teléfono: 3493104

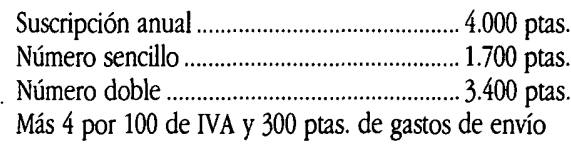

